tropic series, Kerr constant, ionization potentials, isochore and Joule's equivalent.

The general treatment of such of the elements as fall within the literal scope of this volume follows the familiar lines of describing, as appropriate, occurrence, extraction, refining, physical and chemical properties, uses, alloys and compounds, both inorganic and organic; naturally one does not expect to find here all the minutiæ given in "Mellor".

Some disappointment was felt at the lack of detail on the nature of additives for lubricating oils; but, in fairness, it must be admitted that a plea of extenuating circumstances can justifiably be made. On one hand, the number of compounds which have been proposed for the purpose is enormous, while on the other, commercial reticence about those which are actually used is natural enough; moreover, it is doubtful whether the precise nature of some of these products is known.

It would be an invidious task to quote names of contributors; suffice it to say that they are such as to command the respect due to authority in their various fields. On the material side, the now familiar jacket of blue is maintained undimmed, but the stringency of the paper position is reflected in an irregular alternation of colour coupled with quality. The paper is adequate, but it is to be hoped that supplies of at least a uniform tint will be available for subsequent volumes. However, better a "Thorpe" in cream and white rather than no "Thorpe" at all.

B. A. ElLIS

\section{SOCIAL IMPROVEMENT BY EDUCATION}

\section{Some Tasks for Education}

By Sir Richard Livingstone. Pp. vii+98. (London, New York and Toronto: Oxford University Press, 1946.) 5s. net.

$7 \mathrm{HE}$ four lectures in this volume were delivered In September 1945 at the University of Toronto - the first three on the Burwash Foundation and the fourth as the Sir Robert Falconer Memorial Lecture. Although they are not consecutive, all deal with aspects of a single problem-how to improve ourselves and our society by education-and are a valuable corrective to the current obsession of educationists for dealing with means rather than ends. Those who are familiar with Sir Richard's earlier writings will not be surprised to find that, although he examines proposed revisions of curricula to meet the needs of the modern world, he is chiefly concerned to emphasize, as the prior task of education, the need "to inspire and to give a sense of values and the power to distinguish what is first-rate . . from what is not". "It is", he declares, "right to teach the pupil to criticize, but it is even more important to train him concurrently to admire." To him "nothing-not all the knowledge in the worldeducates like the vision of greatness, and nothing can take its place".

The most challenging passages in these lectures are concerned with the training of character. While the creation of the first-rate in art, literature, thought and science must still be-as it has been in the pastthe prerogative of the few, Sir Richard has no doubt about the ability of every human being to create the first-rate in the field of character. His indictment of modern education is its failure to afford this opportunity to every individual. Is it, as he suggests, really true "that in most modern educational schemes the training of character, if not neglected, has been given a subordinate place; that we have very little, if anything, like the concentration on it in Plato's thought and in Arnold's practice?" It may well be that the only way to learn social habits is "by living a life in which such habits automatically develop", but does it necessarily follow that the training of character is difficult, if not impossible, outside the British boarding school ?

Educationists who have to struggle with conditions far inferior to those found in the public schools may justifiably be irritated by Sir Richard's preoccupation with Plato, boarding schools and Periclean democracy. Nevertheless, if he is right that the British boarding school has been the finest factory of citizenship in existence, few will be able to gainsay his conclusion that "we should give to the many some equivalent of the training we have given to the few".

\section{MATHEMATICAL STATISTICS}

\section{Introduction to Mathematical Statistics}

By Assoc. Prof. Paul G. Hoel. Pp. $x+258$. (New York: John Wiley and Sons, Inc.; London : Chapman and Hall, Ltd., 1947.) 3.50 dollars.

NE consequence of the 'export drive' in Britain is likely to be a much increased demand for the mathematical statistician in industry; unfortunately the supply of suitable people is still far too small, and this must largely be attributed to the shortage of teachers and the absence of suitable text-books. Hoel's "Introduction to Mathematical Statistics" seems to me to be an excellent work, and if only it can become generally available it may have a most favourable effect on the situation just described. In spite of the restrictive effeot of the present licensing system, means should be found of introducing the book widely in Britain. Placed in the hands of any intelligent mathematical undergraduate, it will give him in a few weeks not only familiarity with the broad outlines of the subject but also a real understanding of the types of problem with which the research worker in this field is contending.

The first six chapters cover the usual introductory material, in a manner at once accurate and attractive. There follow brief accounts of a variety of more advanced topics: multiple regression, multiple and partial correlation coefficients, discriminant functions, small-sampling distributions $\left(t, \chi^{2}, F\right.$, the range, etc.), non-parametric methods (the theory of runs, the Wald-Wolfowitz treatment of serial correlation), $\chi^{2}$ and tests of goodness of fit, the Neyman-Pearson theory of statistical tests, and the design of experiments (including notes on stratified sampling and sequential analysis). Up-to-date references, exercises both realistic and interesting, the usual tables (together with a very useful one of squares and squareroots) and a satisfactory index complete the work. Of course it is easy to ask for more; one would have liked to see some mention of cumulants, of the characteristic function, of Fisher's exact test for $2 \times 2$ tables, and a more adequate account of maximum likelihood estimation. But the author was probably wise in not overloading the book; it will leave many readers full of a most healthy curiosity. David G. Kandall 